\title{
O modelo cooperativo de extensão dos Estados Unidos: contribuições possíveis para o Brasil
}

\author{
Ana Paula da Silva ${ }^{1}$, Julieta Teresa Aier de Oliveira ${ }^{2}$
}

\section{RESUMO}

Este artigo se propõe a relatar as linhas gerais do sistema de extensão dos Estados Unidos. O objetivo é extrair experiências que possam contribuir para o aprimoramento do serviço brasileiro de Assistência Técnica e Extensão Rural (Ater), em especial no momento em que o tema volta a ter espaço na pauta federal. A maior parte das atividades de extensão naquele país é voltada para o público rural, mas é preciso destacar que algumas abrangem também o público urbano, uma vez que englobam temáticas como nutrição/saúde, administração de gastos/consumo e desenvolvimento de crianças/jovens. Ainda que sejam significativas as diferenças da realidade entre os dois países, o Sistema Cooperativo de Extensão dos Estados Unidos, criado oficialmente há quase 100 anos, mas em formação há cerca de 200, pode oferecer contribuições ao modelo da Ater descentralizado do Brasil. A principal talvez seja a ênfase dada à promoção da autonomia dos produtores rurais e de outros públicos por meio do acesso a conhecimentos que lhes permitam resolver seus próprios problemas e melhorar suas condições de vida. Chamam também atenção a elevada qualificação dos profissionais do sistema de extensão daquele país, incluindo milhares de pesquisadores designados para atender a demandas locais, e a forma como se desenvolve e atualiza continuamente o planejamento de trabalho baseado em necessidades manifestadas pelo público final.

Palavras-chave: Extensão rural, educação não-formal, cooperação.

\section{ABSTRACT}

\section{The USA cooperative extension service: possible contributions to Brazil}

This paper presents in broad lines the current Cooperative Extension Service in the United States of America. Our aim is to make use of experiences that can help improve the Brazilian rural educational system in a moment when the federal government incorporates this theme to its agenda. It is worth noting that most extension educational programs in the United States are aimed at the rural public in agricultural areas, however, they have been reaching more urban audiences in recent years. Even though there are obvious contextual differences between Brazil and the United States, the Cooperative Extension Service - officially created almost 100 years ago but existing in practice for nearly 200 years - can provide contributions to the decentralized Brazilian model. Perhaps the most important contribution is the historical emphasis on "offering information to farmers and other audiences so that they can solve their own problems, and improve their living conditions”. Additionally, it could also be important for Brazilians to consider the emphasis that is placed on staff qualification and on continual evaluation and update of work plans in the Cooperative Extension Service.

Key words: Cooperation, non-formal education, rural extension.

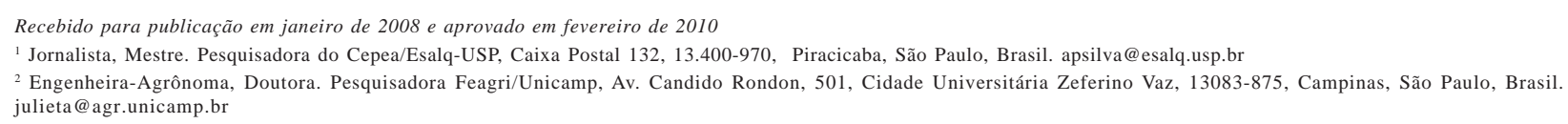




\section{INTRODUÇÃO}

A exemplo da maioria dos países, o desenvolvimento econômico dos Estados Unidos também começou com a agropecuária. Mas, ao contrário do ocorrido no Brasil, o avanço da indústria não esvaziou a atenção dada à agricultura. Ações governamentais de apoio ao setor primário, iniciadas ainda no século XVI - junto com a independência do país -, foram significativamente aprimoradas ao longo do tempo e, como é de amplo conhecimento, sem que os setores da indústria e serviços fossem preteridos.

Em 2006, segundo estimativa da Agência Central de Inteligência (Central Intelligence Agency, 2007), apenas 0,9\% do Produto Interno Bruto (PIB) dos Estados Unidos foi composto pelo segmento primário da agropecuária (produto rural), 20,4\% pela indústria e 78,6\% pelo setor de serviços. Para o Brasil, a mesma fonte indica que a agropecuária representou 8\% do PIB, a indústria 38\% e os serviços corresponderam a $54 \%$.

Já se considerado o total chamado de agribusiness, a participação do grande setor produtor de alimentos, fibras e energia estaria entre 30 e 35\% do PIB dos Estados Unidos no início desta década (Molitor, 2003). No Brasil, a participação do "agronegócio" na economia seria um pouco menor. Segundo dados do Centro de Estudos Avançados em Economia Aplicada (Cepea), da Esalq-USP, sobre o PIB do Agronegócio e do IBGE, acerca do PIB nacional, em 2003 e 2004 o agronegócio representou pouco mais de $28 \%$ do total; em 2005, 25,8\%, no ano seguinte, quase $24 \%$; em 2007, passou para 24,74\%; e em 2008, teria participado com 26,46\% do total (Cepea, 2009).

Apenas para se ter noção dessa representatividade em termos absolutos, para 2007 o Fundo Monetário Internacional (International Monetary Found, 2007) estimou que o PIB dos Estados Unidos seria de 13,77 trilhões de dólares, a preços correntes, e o do Brasil de 1,18 trilhão de dólares. Dessa forma, 0,9\% do PIB total (segmento primário dos EUA) equivaleria a 123,93 bilhões de dólares; os 8\% do Brasil seriam 94,4 milhões de dólares, ou seja, o PIB dos produtores rurais dos EUA é cerca de 1.300 vezes maior do que o dos brasileiros.

Nos Estados Unidos, a "agricultura” historicamente recebe grande apoio dos governos federal, estadual e local. No ano fiscal 2007 (1\%outubro/2006 a 30/setembro/2007), segundo a Associação Nacional das Universidades Estaduais e Escolas Land-Grant (NASULGC - National Association of State Universities and Land-Grant College) $)^{3}$, o total destinado somente pelo governo federal ao Sistema Cooperativo de Extensão - não contemplam apenas agricultura - foi de 1,177 bilhão de dólares. Estados e counties entram com parcelas bem superiores à do gover- no federal. Na Pensilvânia, por exemplo, recursos federais representam cerca de $15 \%$ apenas do total.

A literatura dos EUA repetidamente ressalta que a missão dos programas de extensão é prover informações para que o indivíduo/família/comunidade seja capaz, ele mesmo, de resolver seus problemas. "O Sistema Cooperativo de Extensão ajuda as pessoas a melhorar sua vida por meio de um processo educacional que usa conhecimento científico focado nas questões e necessidades"4 (Rasmussen, 1989). Alguns autores, como Leeuwis (2006), no entanto, são críticos sobre as orientações adotadas para levar a cabo tal propósito. Ressaltam que ainda há pesquisadores que insistem no modelo difusionista, unidirecional, em que o cientista desenvolve profissionais de comunicação e outros intermediários transferem e os produtores meramente aplicam (ou deveriam aplicar) inovações. Atualmente, o Serviço Cooperativo de Extensão divide suas atividades em quatro grandes áreas: agricultura e recursos naturais, economia doméstica/família, desenvolvimento de crianças/jovens (abrange "4-H") e comunidade e desenvolvimento econômico. Conforme as obras consultadas, o conteúdo transmitido pelo Sistema seria baseado em pesquisa de universidades e de estações experimentais, e boa parte do orçamento do Serviço Cooperativo vai para pesquisas voltadas a demandas captadas em campo. Observações da prática de alguns extensionistas mostraram que também experiências bemsucedidas de produtores são repassadas por eles a outros produtores.

Apesar de bastante maduro, o sistema de extensão dos EUA também enfrenta desafios, conforme entrevistas com profissionais da Extensão da Universidade Estadual da Pensilvânia (The Pennsylvania State University ou apenas Penn State). Entre os principais estariam a manutenção de fundos para o Sistema e o aumento da eficiência dos recursos, o que significaria, sobretudo, maior produtividade dos funcionários.

Como consequência da diminuição das verbas especialmente federais ao longo do tempo, estaria aumentando a parcela dada por empresas - os chamados grants - e, com isso, nasceria outro problema: certas atividades correriam o risco de serem pautadas pelos interesses dos financiadores e não pelas demandas do público-alvo.

O objetivo deste trabalho foi compreender em linhas gerais as bases históricas e legais, a estrutura e o funcionamento do sistema cooperativo de extensão dos Estados Unidos. Objetivou-se também realizar pesquisa com técnicos e agricultores visando identificar dinâmicas bem-sucedidas que pudessem enriquecer o sistema brasileiro - feitas, obviamente, as devidas adequações de

\footnotetext{
${ }^{3}$ Disponível em http://www.nasulgc-bac.com/documents.htm - "President’s Budget Request for F.Y. 2008" - CSREES spreadsheet (.xls). Acessado em outubro de 2007.

4 "The Cooperative Extension System helps people improve their lives through an educational process which uses scientific knowledge focused on issues and needs."
} 
contextos histórico, cultural e político. Os levantamentos que proporcionaram o alcance de tais objetivos restringiram-se aos Estados da Pensilvânia e da Maryland. Portanto, os resultados e as discussões propiciados por esses levantamentos não podem ser extrapolados para todo os Estados Unidos, tampouco as sugestões generalizadas para o Brasil. Buscou-se também apurar os desafios que o país com maior tradição no mundo em extensão rural tem enfrentado quanto à extensão e o que tem feito para superá-los.

\section{MATERIAL E MÉTODOS}

Além de pesquisa bibliográfica, foram assistidas aulas de "Design de Programa e Aplicação" e "Métodos de Comunicação e Mídia” ${ }^{5}$ na pós-graduação em $\mathrm{Ag}$ Communication na Penn State. Foi realizada também pesquisa empírica baseada em observações de campo e em entrevistas feitas em setembro e outubro/2007 a partir de convite de técnicos do Serviço de Extensão da Universidade Estadual da Pensilvânia. Os entrevistados formalmente foram: a diretora da regional central do Serviço Cooperativo da Pensilvânia, Mary Jo Depp-Nestlerode, os extensionistas Ronald Hoover e Tom Murphy e os produtores rurais Steve Misera, Luke Howard, William Mason Jr, Larry Fry, Kit Kelley, Leah Tewksbury e D. Richard Snyder.

Esclarece-se ainda que essa pesquisa sobre o funcionamento atual da extensão nos EUA foi realizada com conhecimento prévio da história da extensão rural no Brasil e da retomada dessas atividades nos anos recentes em nosso País.

O objetivo deste trabalho, de forma alguma, portanto, seria o de propor uma nova “importação" do modelo extensionista dos EUA que teria ocorrido nas décadas de 1960 e 70, cujos perversos resultados socioambientais e econômicos já foram amplamente analisados na literatura especializada.

Já em 1975, Ruy Miller Paiva alertava para os impactos negativos da modernização da agricultura brasileira, na qual se circunscreve a extensão rural, que elevaria a pobreza à medida que acelerasse o desemprego, entre outros problemas (Paiva, 1975). Queda (1987) oferece um corolário de autores que discutem propósitos, práticas e desdobramentos da extensão rural brasileira, estabelecendo a estreita relação entre o modelo de extensão e o crédito rural no aprofundamento das desigualdades no campo. Peres (1997) explica que o acesso às tecnologias modernas de produção era possível somente àqueles que ti- nham “capacidade empresarial manifesta”, traduzida na posse de bens que servissem de garantia. Além disso, pesava também o fator educacional. "O problema é que somente os agricultores privilegiados com a herança de uma cultura diferenciada, como a dos descendentes de europeus e orientais, ou aqueles que tiveram acesso a um sistema educacional diferente, puderam absorver as novas tecnologias” (Peres, 1997).

Orivel (1981), citado por Queda (1987), diz: “uma avaliação das atividades desenvolvidas, feita depois de um lapso de alguns anos, irá, inevitavelmente, revelar um aumento das desigualdades entre agricultores.” De fato, no início dos anos 1990, Bergamasco (1992) argumenta que a extensão rural daquele período “foi corresponsável pela reprodução de um modelo de desenvolvimento excludente e autoritário, em que grande massa da população rural foi excluída”, não sendo capaz de cumprir o discurso institucional que pregava a melhora das condições de vida das famílias rurais.

\section{RESULTADOS}

\section{Bases históricas do modelo cooperativo}

Na história da agricultura dos Estados Unidos, a extensão rural representa um capítulo importante, ligado de forma umbilical ao desenvolvimento dos estudos da agricultura no país. Já nos primeiros anos de sua independência, o presidente George Washington inicia seu mandato em 1789 declarando apoio à agropecuária como prioridade e meio de gerar bem-estar aos indivíduos e à nação (Rasmussen, 1989).

Grupos da sociedade também se formaram para fomentar o desenvolvimento da agricultura - em 1785 já existiam sociedades na Carolina do Sul e na Filadélfia para a "Promoção e Progresso da Agricultura" -, por meio da oferta de prêmios pelos progressos obtidos na área, pelo financiamento de palestras e pela publicação das realizações dos membros. Tanto as sociedades agrícolas quanto a imprensa especializada ${ }^{6}$ pressionaram o governo federal para que criasse programas educacionais para os produtores rurais. Em resposta, algumas escolas foram abertas na primeira metade do século XIX (Rasmussen, 1989).

\section{Leis que são pilares da extensão nos EUA até hoje}

Algumas leis implantadas na segunda metade do século XIX têm destaque até hoje no sistema norte-americano de extensão. Em 1862, após a eleição de Abraham

\footnotetext{
${ }^{5}$ Nomes originais em inglês: Program Design and Delivery e Communication Methods and Media, ministrados no departamento de Extensão e Educação Agrícola.

${ }^{6}$ O primeiro jornal agropecuário dos Estados Unidos foi o Agricultural Museum, publicado no distrito de Colúmbia em 1810 - sobreviveu por apenas dois anos. Em 1819 , em Baltimore (Maryland), foi lançado o American Farm, que teve longa vida e grande influência. Outros veículos também foram criados naquele período. De modo geral, incentivavam produtores a relatar suas experiências na superação de problemas (Rasmussen, 1989).
} 
Lincoln (1861) e de vários estados do Sul terem deixado a União - a Guerra da Secessão vai de 1861 a 1865 -, foram aprovadas três leis voltadas à assistência de famílias de produtores rurais e a desenvolver a agricultura do país. Tratava-se de: Lei da Propriedade Rural (Homestead Act), que estimulava a ocupação de terras ao Oeste; Lei Morrill de Concessão de Terras para Escolas (Morrill Land-Grant College Act); e da lei que criou o Departamento de Agricultura dos Estados Unidos (USDA).

A Lei Morrill Land-Grant College, de 1862, representou um impulso à pesquisa e à disseminação de informações para aqueles que não estavam na universidade. Por meio dessa lei, o governo federal deu a cada estado ${ }^{7}$ e território 30 mil acres (12.146 hectares) de terra por senador e "representante" (deputado federal) do congresso.

A maioria deles vendeu seus títulos para negociantes de terra por entre 50 centavos de dólar e 1 dólar o acre $\left(4.047 \mathrm{~m}^{2}\right)$, usando o dinheiro para estabelecer novas escolas de agricultura e mecânica (Rasmussen, 1989). Além das atividades de educação formal, essas instituições deveriam também levar os conteúdos das pesquisas para quem não era aluno regular, ou seja, deveriam realizar extensão. Estavam criadas as universidades Land-Grant 1862, mencionadas sob esse título até os dias atuais, e a base (ainda que informalmente) do Sistema Cooperativo de Extensão dos Estados Unidos.

Em 1890, cursos de extensão começavam a ser ministrados em diferentes localidades, sendo fundada nesse ano "A Sociedade Americana para a Extensão do Ensino Universitário”. Um reforço importante para a estrutura educacional (formal e não-formal) daquele país foi obtido com a Segunda Lei Morrill de Concessão de Terras para Escolas (Second Morrill Land-Grant College Act) ${ }^{8}$, também de 1890. Comumente, essa lei é conhecida como a que estabeleceu as land-grant universities para negros, mas foi muito importante também para as land-grant 1862.

A primeira Morrill Land-Grant College deu terra para a geração de recursos que permitissem a estruturação de universidades em todos os estados que, então, compunham os Estados Unidos, mas não fundos para a continuidade das atividades. Essa segunda estabelece recursos anuais do governo federal para as universidades estaduais (land-grant), desde que não discriminem negros (Rasmussen, 1989)

Com essa lei, também 16 escolas (land-grant colleges) formadas basicamente por negros no sul do país, que eventualmente recebiam recursos do governo federal passaram a ter apoio contínuo, tornando-se as black land-grant colleges 1890. Em 1972, a Universidade Tuskegee (estado do Alabama) passou a integrar esse grupo.

Para o entendimento das legislações atuais e da literatura norte-americana sobre extensão rural, é fundamental ter com clareza a distinção entre esses dois grupos de universidades/escolas: as land-grant de 1862 e as de 1890 e a Universidade de Tuskegee. Especialmente no orçamento federal, elas são citadas de forma separada, havendo legislações complementares que definem recursos para um grupo e para outro.

Em 1994, foram ainda criados, por lei, programas de educação e extensão para indígenas e nativos do Alasca. Nesse sentido, 29 novas Escolas land-grant foram criadas. São as chamadas Escolas e Universidades Tribais (TCUs Tribal College and University) ou Instituições Land-grant 1994. Essas, porém, não desempenham no Serviço de Extensão as mesmas funções que as land-grant 1862 e 1890.

\section{O Serviço Cooperativo de Extensão: da gênese à estrutura e diretrizes atuais}

O Serviço ou Sistema Cooperativo de Extensão (Cooperative Extension Service) foi criado oficialmente em 8 de março de 1914, quando o presidente Woodrow Wilson assinou a lei Smith-Lever. Em 1916, com a assinatura do Memorando de Entendimento entre USDA e as universidades land-grant, foram definidas as funções, em linhas gerais, de cada parceiro. Mas, como citado, muito antes disso, instituições formadas por produtores, universidades, profissionais de estações experimentais e também do USDA já discutiam formas de difundir os conhecimentos que desenvolviam.

Em linhas gerais, o Serviço Cooperativo de Extensão consiste na união de esforços do governo federal, por meio do Departamento de Agricultura (USDA), dos estados, via universidades land-grant, e dos governos locais - county ${ }^{9}$ (condado).

Como resumo das diretrizes do Serviço Cooperativo que persistem desde seu início, podem ser citados os slogans "ajudando pessoas a ajudar a si mesmas" e "aprender fazendo". A definição do Comitê de Organização e Política de Extensão (Extension Committee on Organization and Policy), citada por Seevers et al. (1997), também ajuda a entender: "o Sistema de Extensão Cooperativa é financiado por recurso público, é um sistema de educação não-formal que liga as fontes de pesquisa e ensino do Departamento de Agricultura dos Estados Unidos (USDA) a universidades land-grant e a unidades administrativas regionais”.

\footnotetext{
7 Entre 1861 e 1863, os "Estados Unidos da América” eram compostos por 34 estados.

${ }^{8}$ Apesar de serem land-grant, as universidades de 1890 e também as de 1994 não receberam terra. Esse benefício foi concedido apenas às land-grant (propriamente) 1862 , uma única vez.

${ }^{9}$ County é uma divisão administrativa que pode ser entendida pelos brasileiros como "mesorregião", mas diferindo do conceito que temos de mesorregião pelo fato de o county ter uma estrutura de governo - em geral, três comissários são eleitos pelos moradores e administram um orçamento.
} 
Em linhas gerais, as atividades do Serviço Cooperativo são divididas em quatro grandes áreas: agricultura e recursos naturais, economia doméstica/família/consumidor, desenvolvimento de crianças/jovens (abrange o "4H” - head, heart, hands and health ou cabeça, coração, mãos/ação e saúde) e comunidade e desenvolvimento econômico. Nessas áreas, são desenvolvidos 17 programas definidos pelo Plano de Trabalho ${ }^{10}$ da Universidade Estadual da Pensilvânia (land-grant).

O Serviço ou Sistema Cooperativo de Extensão é coordenado pelo governo federal, via Departamento de Agricultura (USDA). Nesse departamento (equivalente a ministério) existe o Serviço Cooperativo de Pesquisa, Educação e Extensão do Estado (The Cooperative State Research, Education and Extension Service - CSREES), criado em 1994, juntando o Serviço Cooperativo de Pesquisa do Estado e o Serviço de Extensão ${ }^{11}$. O CSREES não trabalha diretamente em pesquisa, educação e extensão, mas atua, sim, como apoiador de programas dos estados e de counties.

O Serviço de Extensão abrange os 50 estados os EUA (48 contínuos mais Alasca e Havaí) e os territórios de Porto Rico, Ilhas Virgens Americanas, Guam, Marianas Setentrionais, Samoa Americana e Micronésia e o Distrito de Colúmbia (onde fica a capital federal, Washington). Em março de 1995, conforme Seevers et al. (1997), 105 universidades land-grant eram abrangidas. Além das land-grant 1862, das 16 land-grant 1890 mais a universidade de Tuskegee estavam incluídas também 29 Escolas landgrant para indígenas de vários estados e nativos do Alasca, criadas em 1994.

Nas universidades land-grant (tanto as do grupo de 1862 quanto as de 1890), que representam o estado no Serviço Cooperativo, existe igualmente uma seção para tratar de todas as questões de educação não-formal e extensão. Essa estrutura é composta por professores, pesquisadores e extensionistas da universidade e das estações experimentais - são oficialmente ligadas às universidades land-grant de 1862.

A relação entre universidades/estados e governo federal no desenvolvimento do Serviço de Extensão é guiada especialmente pelo Memorando de Entendimento entre USDA e as Universidades land-grant, assinado em 1916, e por meio da Aliança Nacional de Universidades Estaduais e Escolas Land-grant (Seevers et al., 1997).

Nos counties, as atividades costumam ser desenvolvidas em conjunto por funcionários do governo federal, do estado (designados pela universidade) e do county, que compõem o escritório local. Os municípios não costumam participar formalmente.

\section{Planejamento contínuo}

As atividades de planejamento coordenado entre as instâncias federal, estadual e local recebem destaque na dinâmica do Sistema Cooperativo de Extensão. Esse assunto, inclusive, é fartamente discutido em disciplinas de pós-graduação em extensão rural ou de comunicação agrícola, por exemplo nas universidades land-grant.

O governo federal (USDA) estabelece as linhas gerais do programa de extensão, iniciativas e objetivos em escopo nacional e provê parte dos recursos - na Pensilvânia, a média tem sido de $15 \%$ do total nos últimos anos. Os estados, por intermédio das universidades land-grant, identificam questões e iniciativas em seu território e alinham tais iniciativas com as diretrizes federais. Eles também são encarregados de desenvolver e disseminar pesquisas e dar treinamento a profissionais que atuam nos counties. Os counties, por sua vez, são o agente local do Sistema, participando intensamente na elaboração e implantação dos programas de educação não-formal. Também, contribuem significativamente com recursos para a realização de tais atividades.

Essa estrutura, segundo obras consultadas, faz com que a distribuição de recursos ocorra de cima para baixo (federal-município), mas a definição dos temas de programas é feita de baixo para cima.

Estima-se que mais da metade do orçamento do Serviço de Extensão seja destinada à agricultura, com ênfase nos aspectos de produção. De fato, segundo a diretora da regional central do Serviço Cooperativo da Pensilvânia, Mary Jo Depp-Nestlerode, em seu estado de 50 a 60\% dos profissionais do Serviço atuam nessa grande área. Cerca de $90 \%$ do orçamento, segundo a diretora, é aplicado em salários.

\section{Modelos de planejamento}

O “programa de planejamento” (programming) inclui a identificação de necessidades, planejamento (propriamente), instrução, atividades de promoção, avaliação e divulgação dos resultados (Boyle, 1985, citado por Boone et al., 2002).

O modelo de planejamento varia de um estado para outro. Conforme Patrick Boyle (1985), citado por Boone et al. (2002), em linhas gerais a maioria dos modelos apresenta similaridade ao dividir a "programação” de educação não-formal de adultos em três núcleos: planejamento, implementação e avaliação. Em cada um há várias subdivisões, dependendo do modelo que se adota. Boone et al. (2002), por exemplo, analisam 13 modelos, sendo um deles do educador brasileiro Paulo Freire ${ }^{12}$.

\footnotetext{
${ }^{10}$ Disponível em http://www.extension.psu.edu/ext_goals.htm

${ }^{11}$ O CSREES é uma das quarto agências do USDA encarregadas de pesquisa, educação e economia. As outras três são: Serviço de Pesquisa na Agricultura (Agricultural Research Service - ARS), Serviço de Pesquisas Econômicas (Economics Research Service - ERS) e Serviço Nacional de Estatísticas Agrícolas (National Agricultural Statistics Service - NASS).

${ }^{12}$ A referência é feita a Freire (1971).
} 
Conforme o sumário do Plano de Trabalho 2007-2011 da CSREES (Serviço Cooperativo de Pesquisa, Educação e Extensão do Estado ${ }^{13}$, para que as universidades landgrant recebam recursos federais é exigido um plano de trabalho a cada quatro anos e um relatório anual sobre as pesquisas e atividades de extensão desenvolvidas com recursos das quatro principais fontes federais de financiamento: lei Hatch, lei Evans-Allen, lei Smith-Lever e lei conhecida como "Programas de Extensão 1890". Esses relatórios orientam também ajustes ao plano quadrianual.

A coordenação do planejamento, seguindo a distribuição de recursos - já citada -, ocorre de cima para baixo (federal para local), com o objetivo de obter padronização na dinâmica desenvolvida em toda a área de abrangência do Serviço Cooperativo - 50 estados mais territórios. Já a definição do conteúdo de cada programa seria feita de baixo para cima, segundo obras consultadas e também entrevistas, com a utilização de várias metodologias para o levantamento de questões com o público local.

No county de Lycoming, Pensilvânia, por exemplo, o educador-extensionista (extension educator) Thomas Murphy, responsável pela área de agricultura, se reúne com diferentes grupos de agentes do agribusiness local a maioria é produtor - e apura com eles suas demandas. Esse profissional, então, faz um programa de trabalho para a sua área e o insere on-line no sistema do Serviço Cooperativo. Os educadores-extensionistas das outras áreas fazem o mesmo, sendo assim desenhado os planos local, estadual (soma dos counties) e federal de extensão. Essa dinâmica se repete anualmente, e todos os programas são supervisionados quanto à eficiência.

\section{Profissionais do Sistema Cooperativo de Extensão}

A classificação profissional dos funcionários que trabalham com extensão varia entre estados. Algumas landgrant dão status de professor a parte dos funcionários, enquanto outras adotam colocações diferentes. Em linhas gerais, os profissionais do Sistema de Extensão se dividem em cinco grupos: administração, programação, agente do county, paraprofissional ou assistente do programa e pessoal de apoio ou escritório. Subdividindo essas funções, pode-se ter 16 áreas de competência, incluindo pesquisa aplicada, comunicação e desenvolvimento de carreira (Seevers et al., 1997).

No caso da Pensilvânia, os 67 counties estão divididos em seis grandes regiões. Cada diretor tem autonomia para indicar e destituir o representante no county, bem como os demais funcionários de sua área. A diretora regional entrevistada, Mary Jo Depp-Nestlerode, por exem- plo, era responsável por 17 counties, administrando quase 100 funcionários. Em todo o estado, seriam cerca de 1 mil funcionários que, no ano fiscal 2007, teriam atendido a 473.021 pessoas nos 17 programas do estado.

Segundo entrevista com o educador extensionista Thomas Murphy, da regional dirigida por Mary Jo, no county de Lycoming cerca de dois terços dos produtores rurais seriam atendidos por ele, único representante de campo para atividades de agricultura naquele county. Ficariam de fora, segundo Murphy, especialmente produtores que dedicam à agricultura parte apenas de seu tempo, sendo muitos desses de pequeno porte.

Além dos funcionários contratados, milhares de voluntários reforçam - chegam mesmo a ser imprescindíveis - o Sistema, com diversas especialidades. Na Regional Central da Pensilvânia, eram cerca de 1 mil voluntários e, em todo o estado, 12 mil, conforme a diretora Mary Jo. Os que trabalham diretamente com o público, dando orientações, recebem um seguro (Liability insurance) que os protege contra processos na justiça que venham a ser movidos por produtores, por exemplo, os que consideram ter tido prejuízo ao seguir uma recomendação - todos os extensionistas também têm esse seguro. Além dessa categoria, segundo a diretora Mary Jo, haveria cerca de outros 13 mil que apoiariam eventualmente as atividades de Extensão, sem receber nada.

Em termos de educação formal, é requerido de agentes de county, programadores e administradores, no mínimo, diploma de bacharel. A maioria dos estados, porém, requer de seus funcionários/candidatos também título de mestre em áreas afins às atividades que vão desenvolver no Sistema de Extensão. A "Extensão" (extension education) é reconhecida como uma área específica de conhecimento, com cursos de graduação e pós-graduação em várias universidades dos EUA ${ }^{14}$.

No Estado da Pensilvânia, segundo Mary Jo DeppNestlerode, em 2007 havia cerca de 300 extensionistas de campo, e a maioria tinha mestrado. Além desses, aproximadamente 100 pesquisadores/professores do Sistema tinham doutorado - a menor parte desses se ocuparia de pesquisa e aulas em cursos formais da Universidade. Conforme a diretora, como estímulo à melhora da qualificação, que levaria a aumento de salário, o funcionário do Sistema teria $75 \%$ das despesas com a universidade (Penn State) cobertas e ainda a dispensa do trabalho para cursar três disciplinas por semestre.

Entre os extensionistas de campo, os salários variavam, em 2007, entre 31.284 e 63.528 dólares/ano; de 2.600 a 5.300 dólares/mês. Para um funcionário do Sistema que não fosse bacharel, o menor salário seria de 15.852 dóla-

\footnotetext{
${ }^{13}$ Disponível em: www.csrees.usda.gov/business/reporting/planrept/pdf/07_pow_summ.pdf

${ }^{14}$ A primeira a criar uma graduação em extensão foi a Universidade de Wisconsin, em 1929.
} 
res/ano; 1.320 dólares/mês. As despesas com salários, conforme citado, chegam a representar quase $90 \%$ do orçamento do Sistema, segundo a diretora Mary Jo. Justamente por esse motivo, um dos desafios seria aumentar a eficiência desse pessoal.

Na maioria dos estados, ao ser contratado o funcionário do Sistema recebe treinamento, incluindo aulas sobre filosofia, estrutura e políticas do Serviço, formas de transmissão de conteúdos e avaliação dos programas. Em muitos estados, o novo funcionário começa sua carreira desenvolvendo um planejamento profissional (para si mesmo). São ministrados também treinamentos periódicos sobre novas tecnologias de comunicação e feitas, com frequência, atualizações sobre as pesquisas mais recentes. Todos os funcionários são também avaliados sobre suas performances profissionais.

\section{Financiamentos}

O Serviço Cooperativo de Extensão é financiado em grande parte por recursos de impostos coletados pelos governos federal, estadual e pelo county, mas recebe também doações individuais e de instituições/empresas, recursos provenientes de serviços específicos pagos por usuários, além de contribuições obtidas pelo grupo de desenvolvimento de crianças/jovens (4-H).

No nível local (county), não há impostos específicos que destinem recursos para o Serviço de Extensão, sendo o montante definido pelos comissários, os quais são eleitos pelos residentes. Para supervisionar os gastos, existe um grupo de voluntários (não funcionários do Sistema) que se candidata e pode ser eleito. Na Pensilvânia, esses voluntários são eleitos para atuar por três anos, sendo possível uma reeleição.

Quanto ao estado, os recursos para o serviço de extensão podem ser alocados nos orçamentos das universidades ou para extensão propriamente (Seevers et al., 1997).

A destinação de recursos do governo federal se dá principalmente por meio de quatro leis. A Lei Hatch ${ }^{15}$, criada em 1887, que provê anualmente recursos para estações experimentais de agricultura dos estados. Essas estações são subordinadas aos departamentos de agricultura das universidades land-grant de 1862. A lei EvansAllen ${ }^{16}$, de 1890, por sua vez, prevê recursos para o financiamento de pesquisas agrícolas às universidades landgrant de 1890, mas essas instituições devem prover outros $50 \%$ dos recursos obtidos em fontes diferentes do governo federal. Além de criar o Serviço Cooperativo de Extensão, a lei Smith-Lever ${ }^{17}$, de 1914, também estabele- ceu recursos federais para tais atividades. A lei requer que os estados forneçam o mesmo montante proveniente de fontes diferentes da união. Outra parcela considerável de recursos federais vem por intermédio dos chamados "Programas de Extensão para as land-grant 1890". Para receber os recursos, o estado deve prover $50 \%$ do total federal.

\section{Composição do orçamento}

A dinâmica de um escritório "local” do Serviço de Extensão consiste no trabalho conjunto de profissionais contratados pelas diferentes fontes de recursos - governo federal, estado, o qual recebe e administra os grants, e county.

Nos anos recentes, a participação federal tem se mantido estagnada ou mesmo diminuído. Em termos absolutos, o aumento dos recursos não tem sequer acompanhado a inflação. Segundo a Associação Nacional das Universidades Estaduais e Escolas Land-Grant (NASULGC) ${ }^{18}$, de 2004 para 2005 as verbas federais aumentaram 4,4\%; de 2005 para 2006 o reajuste foi de 1,8\%; de 2006 para 2007 (valor informado em outubro/07 não era o final), o montante foi praticamente o mesmo; para 2008 estava prevista redução de quase 14\% frente ao total de 2007.

Caso o governo federal tenha destinado mesmo 1,014 bilhão de dólares para a extensão em 2008, esse foi o menor valor desde $2002^{19}$.A comparação entre o montante previsto inicialmente e o total efetivamente destinado em cada ano-fiscal mostra que costuma haver aumento ao longo do período. A participação dos estados, de modo geral, também estaria estagnada, acompanhando no máximo a inflação. No Estado da Pensilvânia, por exemplo, o orçamento do Serviço de Extensão em 2006/07 foi por volta de 78 milhões de dólares, e em 2007/08 estava previsto de 78,8 milhões de dólares, crescimento de apenas $1 \%$. Do total $2007 / 08$, 39\% veio do estado, $16 \%$ do governo federal, $16 \%$ do county, $21 \%$ de doações de empresas (grants), especialmente via contratação de funcionários, e $8 \%$ de fontes alternativas do county (diferentes de recurso proveniente de impostos) ${ }^{20}$.

Dado esse quadro, o principal desafio do Sistema, na opinião da diretora Mary Jo, tem sido justamente manter os recursos. O aumento dos grants de empresas é positivo, mas a sua participação crescente no total traz preocupações quanto à influência que pode exercer sobre as atividades de extensão. Nas palavras de profissionais consultados da sociologia rural, haveria o risco de ocorrer a "privatização" do Serviço.

\footnotetext{
${ }^{15}$ Detalhes sobre esta lei: http://www.csrees.usda.gov/business/awards/formula/hatch.html

${ }^{16}$ Mais informações sobre esta lei: http://www.csrees.usda.gov/business/awards/formula/evansallen.html

${ }^{17}$ Mais informações sobre esta lei: http://www.csrees.usda.gov/business/awards/formula/smithlever.html

${ }^{18}$ Disponível em http://www.nasulgc-bac.com/documents.htm - "President’s Budget Request for F.Y. 2008" - CSREES spreadsheet (.xls). Acessado em outubro/07.

${ }^{19}$ As autoras analisaram os orçamentos de 2002 para frente.

${ }^{20}$ Informações obtidas em entrevista com a diretora regional do Serviço Mary Jo Depp-Nestlerode.
} 
Em outros estados, a proporção de recursos dos diferentes financiadores pode ser diferente, mas a preocupação com a obtenção de fundos seria comum.

\section{Observações de campo: interação entre pesquisa e prática}

A pesquisa empírica baseou-se em observações de campo e entrevistas com sete produtores dos Estados da Pensilvânia e de Maryland visitados pela entrevistadora a partir de convite de técnicos do Serviço de Extensão da Universidade Estadual da Pensilvânia. Quatro dos sete entrevistados trabalhavam exclusivamente com sistemas orgânicos e um estava em transição de convencional para orgânico. A despeito do perfil dessa amostra, sistema orgânico representa apenas um pequeno percentual da produção dos EUA, ou seja, essa amostra não é representativa da produção daquele país.

Conforme alguns autores, as preocupações agroambientais, menosprezadas em instâncias oficiais em décadas anteriores, encontram cada vez mais interlocutores para um diálogo que estaria proporcionando uma transição do modelo convencional de produção para um outro mais sustentável. Nos EUA, mudanças nas orientações de pesquisa e extensão foram oficializadas com o "FAIR Act” (Lei Federal de Reforma e Aprimoramento da Agricultura), que vigorou de abril/96 a setembro/02. O FAIR Act de 1996 trouxe mudanças significativas para a política agrícola americana como um todo, que passou a ser orientada por critérios de mercado. Essa lei suspendeu o pagamento direto de preços pré-fixados e os programas de redução de área plantada, pilares do sistema de suporte de preços ao setor agrícola daquele país. O FAIR Act reorientou também as estratégias de pesquisa, educação e economia de modo a estimular programas de pesquisa e extensão agropecuária focados na sustentabilidade da produção (Veiga, 1997).

É preciso ainda destacar que no Estado da Pensilvânia a influência de modelos alternativos, bem como de participação ativa do produtor, é acentuada pela atuação de profissionais do Instituto Rodale ${ }^{21}$, focado em "agricultura regenerativa” e instalado nesse estado desde a década de 1930. De fato, o discurso dos produtores entrevistados revelou mais que a busca por nicho de mercado; os cinco (inclui-se o produtor em transição) preocupavamse com a sustentabilidade dos recursos naturais.

O fazendeiro, que dividia suas terras entre a produção orgânica e a convencional, William Mason Jr, de 55 anos, proprietário de 850 acres $^{22}$ (344 hectares) próximos à pequena cidade de Centreville, em Maryland, destacou que ele era a terceira geração que trabalhava com aquelas terras e que elas deveriam durar para muitas outras. Nesse contexto, ele e o vizinho de propriedade, Luke Howard, de 42 anos, já com seus 200 acres $^{23}$ (81 hectares) convertidos em produção orgânica de soja e milho, recebiam dois profissionais do Instituto Rodale e um extensionista da Penn State para discutir o controle de ervas daninhas. A conversa entre produtores e técnicos, bastante fundamentada por ambas as partes, se deu no meio da plantação, com análise visual da situação e apontamento de alternativas, com relatos de pesquisas desenvolvidas e de experiência em outras localidades.

O acompanhamento da visita de extensionista da Penn State à propriedade de Steve Misera, 46 anos, também se deu em contexto semelhante. Os 80 acres $^{24}$ (32 hectares) que ele tem em Butler, Pensilvânia, já estavam todos destinados à produção orgânica de grãos, galinhas, ovos e boi. Professor técnico de agricultura, Misera destacava alguns malefícios do uso continuado de fertilizantes químicos e agrotóxicos e dizia que "multinacionais de químicos não veriam um centavo dele”.

Ronald Hoover, engenheiro-agrônomo e mestre em produção vegetal, extensionista da Penn State, discutia com Misera algumas opções de "cobertura de inverno" (cover crop) - a qual serviria de adubo para a próxima lavoura. O pesquisador apresentou alguns resultados de trabalhos experimentais e, juntamente com o produtor, definiu o conjunto de sementes que seriam semeadas em uma parte da propriedade.

Nessa situação, o produtor não estava sendo apenas orientado sobre as melhores variedades para cobertura de inverno. Participava também de experimento de pesquisa da Penn State, cujos resultados poderiam ser propagados para outras propriedades. Vale citar que o extensionista participou efetivamente no preparo das sementes, na calibragem da plantadeira e do semeio - atividade essa que se estendeu para depois do pôr do sol.

Esse tipo de "parceria” entre produtores, que cedem área para experimentos, e o Serviço de Extensão é comum na Pensilvânia (PA) e, possivelmente, em outros estados. O outra mostra de tal relação foi vista no município de Williamsport (PA).

No meio da produção convencional de soja, um pequeno talhão era cultivado com variedade suscetível à ferrugem asiática. As plantações dos EUA atualmente não têm esse fungo e, para supervisionar uma ocorrência, o Serviço de Extensão teria como estratégia manter pequenos talhões de variedades suscetíveis em várias propriedades em todo o país. Assim, haveria um monitoramento

\footnotetext{
${ }^{21}$ Interessados podem acessar: www.newfarm.org

${ }^{22}$ De acordo com o proprietário, um acre $(4.047 \mathrm{~m} 2)$ custava cerca de US\$ 6.000 na sua região em set/07.

${ }^{23}$ Esse produtor estimou em US\$ 8.000/acre de sua propriedade em setembro/07.

${ }^{24}$ De acordo com o proprietário, um acre $(4.047 \mathrm{~m} 2)$ custa cerca de US\$ 10.000 na sua região.
} 
sistemático da incidência do fungo nas lavouras. Em Williamsport, o plantio foi coordenado pelo extensionista Tom Murphy a pedido de pesquisadores da Penn State que estariam integrados com os pesquisadores de outros estados num programa nacional de monitoramento da doença.

O proprietário dessa área, Larry Fry, de 67 anos, confirmou o hábito de participar das pesquisas do Serviço de Extensão e mostrava-se bastante satisfeito com a colheita de quase 73 sacas de 60 quilos por hectare ${ }^{25}$. Para esse produtor, os serviços gratuitos dos extensionistas o ajudariam a aumentar em cerca de $20 \%$ sua receita ${ }^{26}$.

Noutro encontro de extensionista com produtores, a discussão era sobre como afastar na medida certa insetos das plantações de abóbora orgânica. Os produtores Kit Kelley, 55 anos, dono de 39 acres (6,5 hectares), e Leah Tewksbury, 40 anos, proprietária de 1,5 acre $\left(6.000 \mathrm{~m}^{2}\right)^{27}$ de Lewisburg (Pensilvânia), já tinham feito alguns experimentos e apresentavam gráficos com os resultados comparativos. Ainda assim, não haviam encontrado solução, tampouco os extensionistas. Era caso, então, para ser levado a pesquisadores da Penn State, que trabalhariam a partir daquela demanda.

Pela dinâmica do Serviço, além dos resultados de pesquisa, também experiências de outras regiões são levadas adiante. Um exemplo desse aproveitamento foi visto na propriedade de D. Richard Snyder, de 72 anos. Em busca de maior receita proveniente de seus 200 acres (81 hectares), o produtor de Montourville (PA) aceitou a sugestão do extensionista de criar um "labirinto" (maze) para diversão de crianças no meio de uma pequena área de sorgo. Com as plantas crescidas, são feitas trilhas, colocadas algumas placas com personagens infantis e preparada, do lado de fora, uma pequena área para lanche. Ônibus com dezenas de crianças chegam diariamente no outono, pagando cada uma cinco dólares. Pouco antes do inverno, o produtor colhe o sorgo e o vende a produtores de leite, otimizando a receita antes limitada a uma safra de milho/ano. Segundo o produtor, a extensão o teria ajudado a elevar em $30 \%$ sua receita.

\section{DISCUSSÃO}

Ao contrário da extensão rural difusionista realizada no Brasil na época da Revolução Verde (décadas de 1960 e 1970), quando se importou o sistema norte-americano então vigente, o que se constatou na literatura mais atual e em acompanhamentos ao trabalho de extensionistas do
Estado da Pensilvânia e do Instituto Rodale foi diálogo de qualidade entre técnicos e produtores de diferentes escalas.

Tal respeito à opinião do produtor, que argumenta criticamente com o extensionista, definindo uma dinâmica de "fazer junto", em tese começaria na elaboração do Plano de Trabalho (local/estadual/nacional), que é orientado por demandas locais. Conforme vários autores dos Estados Unidos, esse modelo tem grande justificativa: sem a efetiva participação do público final, sem considerar experiências, cultura, hábitos locais, nenhum sistema de educação funciona. O difusionismo de outrora teria perdido espaço por sua multicomprovada ineficácia.

Tendo em vista a restrita amostra desta pesquisa, é preciso ressalvar que dinâmicas consideradas positivas naquela região dos Estados Unidos poderiam ser sugeridas apenas para regiões brasileiras com características assemelhadas àquela, em que propriedades de pequeno e médio portes avizinham-se com outras mais extensas, produtoras de commodities, em geral com grau de tecnificação elevado. No Brasil, pode-se entender que isso representa partes das regiões Sul e Sudeste.

Entre as características positivas do atual Sistema Cooperativo de Extensão visto especialmente no Estado da Pensilvânia, pelo menos quatro podem ser destacadas como possíveis contribuições às citadas regiões brasileiras: atuação extensionista enquanto prática educativa promotora dos desenvolvimentos individual e coletivo; profissionais qualificados e motivados para a extensão/ educação; estrutura de pesquisa efetivamente à disposição das demandas locais; e realizar planejamento coordenado - ainda que o modelo seja descentralizado -, com atualizações e capacitações periódicas.

A primeira e talvez mais importante seja a premissa de educar e educar-se (Freire, 1971) como prática extensionista emancipadora na resolução dos problemas e melhoria das condições de vida. No Brasil, mesmo com a Nova Política Nacional de Assistência Técnica e Extensão Rural - Nova Ater ${ }^{28}$ - e com algumas iniciativas públicas estaduais e de entidades não-governamentais, que pautam suas ações no diálogo e práxis capazes de potencializar o crescimento dos sujeitos como cidadãos, não se pode dizer que haja um movimento nacionalmente expressivo nesse sentido.

Diretamente relacionado à educação e à produção de pesquisas e de novos conteúdos (teóricos e práticos) estão as universidades e os institutos de pesquisa. Insti-

\footnotetext{
${ }^{25}$ A média do Centro-Oeste brasileiro na safra 2006/07 foi de 48,5 sc/ha, segundo a Companhia Nacional de Abastecimento. Veja Quadro 20 em www.conab.gov.br/conabweb/ download/safra/estudo_safra.pdf

${ }^{26}$ No total, este produtor teria 370 acres (62 hectares); cada acre foi avaliado por ele em US\$ 5.000

${ }^{27}$ Ambos avaliaram em US\$ 3.000 um acre em sua região.

${ }^{28}$ Sobre conceitos, princípios e metodologia da Nova Política de Ater, consultar Caporal (2003) Bases para uma Nova Ater Pública, disponível em www.pronaf.gov.br/dater, e Ministério do Desenvolvimento Agrário, Política Nacional de ATER, disponível em www.pronaf.gov.br/dater/index.php?sccid=438.
} 
tuições públicas e também algumas privadas exibem em suas divulgações institucionais o mesmo tripé característico das universidades land-grant norte-americanas: ensino, pesquisa e extensão. Na prática, porém, o que é efetivamente realizado de extensão no Brasil pelas universidades ou, ainda, quanto essas contribuem com pesquisas que são de interesse de produtores de suas regiões? Existe coordenação entre os departamentos de uma mesma universidade? Existe coordenação entre as universidades públicas - ao menos - de um mesmo estado? Como não foi feita pesquisa específica sobre esse tema, por ora ficam apenas as indagações.

Outro ponto aparentemente bem-sucedido na dinâmica dos EUA - da Pensilvânia, ao menos - que poderia ser considerado pelos brasileiros é a qualificação dos profissionais e a integração de diferentes especialistas. Analise-se, por exemplo, a importância do extensionista contar com pesquisador que trata problemas do campo.

Algumas ações do governo federal, como a formação de profissionais para atuarem nas áreas de assentamentos rurais (Pronera - Programa Nacional de Educação na Reforma Agrária) e as capacitações dos agentes da Ater pelo Departamento de Assistência Técnica e Extensão Rural (Dater), do MDA, em parceria com universidades, de fato já são visíveis e lançam algum otimismo sobre a educação não-formal.

O terceiro grande aspecto sugerido aos administradores da extensão rural brasileira é planejamento coordenado. Destaca-se que planejamento coordenado não rivaliza com modelo descentralizado, pelo qual as ações são determinadas em níveis estaduais e/ou locais. Planejamento e coordenação pelo governo federal, com participação de estados e municípios, poderiam otimizar recursos e resultados.

Não se pretendeu neste artigo fazer uma análise meticulosa da Ater brasileira. Como se sabe, o desafio dos brasileiros para a implementação eficiente de um sistema de educação não-formal para o campo é grande. Mas a aposta nos resultados de um sistema participativo, eficiente e emancipador faz com que se reúnam forças para trabalhar nesse sentido. O governo tem recursos e dever de prover seus cidadãos contribuintes, mas, além deste, outras combinações espontâneas da sociedade também podem gerar resultados significativos. Aposta-se na ação individual, que leva à transformação coletiva.

\section{AGRADECIMENTOS}

Aos professores Geraldo Sant’Ana de Camargo Barros, coordenador científico do Cepea/Esalq-USP, pelo incentivo intelectual e pelo apoio financeiro à primeira autora, e Thomas Bruening, da The Pennsylvania State University.

\section{REFERÊNCIAS}

Bergamasco SMPP (1992) Extensão rural: passado e presente no discurso e na prática. In: Cortez LAB \& Magalhães PSG (Coord.) Introdução à engenharia agrícola. Campinas, Editora da UNICAMP. p.353-363.

Boone EJ, Safrit RD \& Jones J (2002) Developing programs in adult education, 2nd. ed. Long Grove, Waveland Press, Inc. $307 p$.

Caporal FR (2003) Bases para uma nova ATER pública. Disponível em: <http://www.pronaf.gov.br/dater>. Acessado em: 25 de novembro de 2007.

Central Intelligence Agency (2007) The world factBook 2007 Field listing GDP - composition by sector. Disponível em: <https://www.cia.gov/library/ publications/the-world-factbook/ fields/2012.html> Acessado em: 22 de setembro de 2007.

Cepea - Centro de Estudos Avançados em Economia AplicadaEscola Superior de Agricultura Luiz de Queiroz/USP (2009) PIB do Agronegócio - Dados de 1994 a 2008. Disponível em: <http:/ /www.cepea.esalq.usp.br/pib/> Acessado em: 12 de julho de 2009.

Freire P (1971) Extensão ou comunicação? Rio de Janeiro, Ed. Paz e Terra. 93p.

International Monetary Found (2007) World economic and financial surveys - World economic outlook database April 2007 Edition. Disponível em: <http://www.imf.org/external/pubs/ft/ weo/2007/01/data/index.aspx> Acessado em: 22 de setembro de 2007

Leeuwis C (2006) Communication for rural innovation: Rethinking agricultural extension, 2nd. ed. Oxford, Blackwell Publishing. 412p.

Molitor GTT (2003) Food and agriculture in the 21st Century: Rethinking our paradigms. The Futurist Vol. 37 Issue 5. Disponível em: <http://www.agbioworld.org/newsletter_wm/ index.php?caseid=archive\&newsid=1770>Acessado em: 22 de setembro de 2007.

Paiva RM (1975) Os baixos níveis de renda e de salários na agricultura brasileira. In: Contador CR (Org.) Tecnologia e desenvolvimento agrícola. Rio de Janeiro, IPEA. p.195-231.

Peres FC (1997) Alguns condicionantes do desenvolvimento da agricultura brasileira. Piracicaba. Preços Agrícolas, 128:9-14.

Queda O (1987) A extensão rural no Brasil: da anunciação ao milagre da modernização agrícola. Tese de Livre Docência. Escola Superior de Agricultura “Luiz de Queiroz”, Piracicaba, 201p.

Rasmussen WD (1989) Taking the university t the people: Seventy-five years of Cooperative Extension. Ames, Iowa State University Press. 300p.

Seevers B, Graham D, Gamon J \& Conklin N (1997) Education through cooperative extension. Albany, Delmar PublishersInternational Thomson Publishing Company. 288p.

Veiga JE (1997) A transição agroambiental nos Estados Unidos. In: Almeida J \& Navarro Z (Orgs.) Reconstruindo a agricultura: Idéias e ideais na perspectiva de um desenvolvimento rural sustentável. Porto Alegre, Editora da Universidade (UFRGS). p.123-143. 